UDK: 621.38:620.9

DOI: $\underline{\text { https://doi.org/10.24867/12BE08Vasic }}$

\title{
PRIMENA NEURALNIH MREŽA ZA DETEKCIJU PROPADA NAPONA NA PRIMERU RADA TEST MREŽA
}

\section{APPLICATION OF NEURAL NETWORKS FOR VOLTAGE DIPS DETECTION ON THE EXAMPLE OF TEST GRIDS OPERATION}

\section{Ivan Vasić, Vladimir A. Katić, Aleksandar M. Stanisavljević, Fakultet tehničkih nauka, Novi Sad}

\section{Oblast - ELEKTROTEHNIKA I RAČUNARSTVO}

Kratak sadržaj - U radu je obrađena primena pametnih tehnologija, odnosno neuronskih mreža u energetici, pri čemu se njihova primena vrši u softverskom paketu MATLAB. Data je studija slučaja detekcije kvarova u IEEE13 test mreži sa dodatim obnovljivim izvorom energije. Studija slučaja pokazala je da primena neuronskih mreža može biti od velike koristi u ovoj grani, što pokazuju rezultati, kojima je dokazano da se obučavanje neuronske mreže pokazalo ispravnim u cilju detekcije kvarova.

Ključne reči: IEEE 13-bus test mreža, neuronske mreže, propadi napona.

Abstract - In the thesis applications of neural networks in power engineering is described, especially in MATLAB software package. A case study of fault detection in the IEEE13 test grid with inserted renewable energy resource is given. It is shown that neural network gives great result in this branch, following impressive results for fault detection in IEEE13 test grid.

Keywords: IEEE 13-bus test grid, neural networks, voltage dips.

\section{UVOD}

Razvoj tehnologije doprineo je mnogo većim mogućnostima i sposobnostima današnjih računara, odnosno značajnom poboljšanju njihovih performansi. To je dovelo do njihove intenzivnije u različitim oblastima, od svakodnevnog života, medicine, telekomunikacija, pa i do energetike. Značaj računara u energetici doprineo je digitalizaciji upravljanja, čime se povećava sigurnost rada sistema, process održavanja (čuvaju se ljudski životi) i planiranja. Sve ovo čini osnovu formiranja tkzv. Pametnih mreža, koje se odlikuju velikim udelom IT tehnologija.

Za operativni rad mreža, posebno je važna njihova primena za detekciju i lokalizaciju kvarova, njihovu izolaciju, pravilnu raspodelu opterećenja, brzu rekonfiguraciju mreže, kontrolu rada sistema i dr. Analiza velikog broja podataka zahteva primenu ,veštačke inteligencije“, odnosno neuronskih mreža, koje rešavaju probleme prepoznavanja šablona, predikcije, klasifikacije, upravljanja sistemom [1].

\section{NAPOMENA:}

Ovaj rad proistekao je iz master rada čiji mentor je bio dr Vladimir Katić, red. prof.
Tradicionalni postupak rešavanja, gde se algoritmi pišu za neki specifični problem, uslovljava dobro poznaje domena, kao i sam problem, kao i postojanje adekvatnog rešenja. Kod metode mašinskog učenja, postupak obuhvata postavljanje početnog stanja, odnosno učitavanje adekvatnih ulaznih podataka, a zatim se dobijeni rezultati ocenjuju po unapred definisanim kriterijumima. Ukoliko odgovori zadovoljavaju kriterijume, daje se pozitivna ocena i obrnuto, na bazi čega se ažurira stanje metode. Time ona u narednoj iteraciji daje bolje, tj. tačnije rešenje, odnosno dobijeni rezultat u većoj meri odgovara stvarnom stanju. Ovaj proces se ponavlja iterativno dok se ne postigne željena tačnost [2].

$\mathrm{U}$ ovom radu razmatrana je $\mathrm{i}$ razvijena primena neuronskih mreža za detekciju propada napona u mreži, čime se omogućuje efikasniji i kvalitetniji rad, pogotovu u slučaju većeg prisustva obnovljivih izvora. Radi univerzalnosti predloženog rešenja, za testiranje je uzeta standardna IEEE test mreža sa 13 sabirnica (IEEE 13-bus test grid) modifikovana dodatkom obnovljivih izvora.

\section{MODIFIKOVANA IEEE 13-BUS TEST MREŽA}

Na slici 1 dat je prikaz korišćenog referentnog modela distributivne mreže u okviru ovog rada. Radi se IEEE 13 - bus test mreži, koja je modifikovana priključenjem fotonaponske (FN) elektrane nominalne snage $250 \mathrm{~kW}$ preko transformatora $0.25 / 4.16 \mathrm{kV} / \mathrm{kV}$ kod sabirnice 671 . Za potrebe ovog rada, pretpostavljena je standardna vrednost solarne iradijacija od $1000 \mathrm{~W} / \mathrm{m}^{2}$, kao i njena nepromenljivost $\mathrm{u}$ opsegu razmatranja. Kvar je generisan na sabirnici 633, a detekcija sa predloženom primenom neuronske mreže je urađena na mestu priključka FN elektrane.

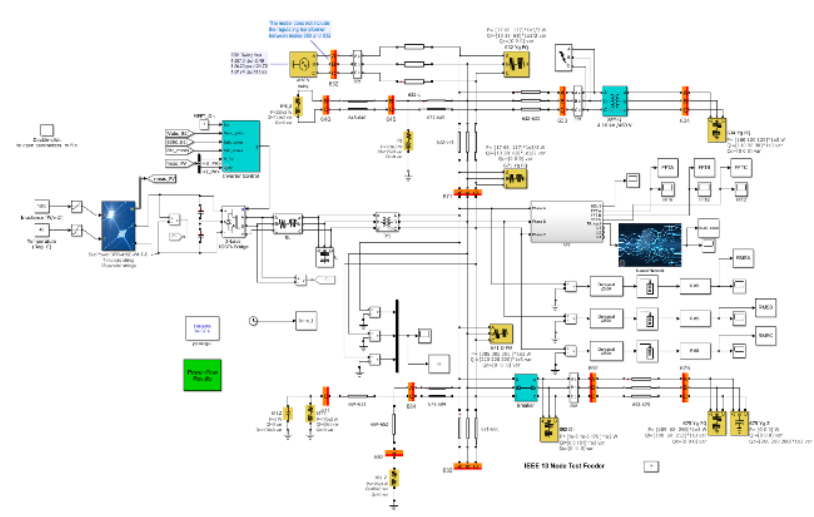

Slika 1. Modifikovana IEEE 13 - bus test mreža 
Prema IEEE standardu 1159-2009 propadi napona definisani su kao redukcija napona u rasponu od $10 \%$ do $90 \%$ od nominalne vrednosti napona, kada je frekvencija sistema nominalna i kada je trajanje poremećaja u rasponu od pola periode do jednog minuta [2]. Naponski signal ne može biti direktno iskorišćen za detekciju ili klasifikaciju događaja i poremećaja u EES. Zbog toga jednostavna i najčešće korišćena metoda je bazirana na direktnom proračunu efektivne vrednosti napona iz sinusnog oblika napona (RMS metoda):

$$
V_{r m s}=\sqrt{\frac{1}{N} \sum_{i=1}^{N} v_{i}^{2}}
$$

Efikasnije i vremenski brže rešenje je umesto RMS vrednosti koristiti metodu harmonijskog otiska (engl. Harmonic Footprint), u kojoj se detekcija bazira na redukovanom setu harmonika [2].

\section{NEURONSKE MREŽE}

Neuronske mreže (engl. Neural Networks - NN) predstavljaju sisteme za procesiranje informacija, poseduju mogućnost učenja, memorisanja i generalizacije na osnovu dobijenih podataka za obučavanje. Sastoje se od velikog broja gusto povezanih procesorskih elemenata, tzv. čvorova, koji uobičajeno rade u paraleli i koji su organizovani po nekim regularnim arhitekturama. Razvoj neuronskih mreža nastao je motivacijom da se modeliuje ponašanje (bioloških) neurona u mozgu.

Neuroni se grupišu u slojeve. U okviru jednog sloja, svaki neuron tog sloja dobija isti ulaz. Slanjem istog ulaza u različite neurone postiže se otkrivanje različitih informacija i donošenje novih zaključaka o ulaznim podacima. To se postiže tzv. težinama, odnosno težinskim signalima, koji se definišu za svaki ulazni signal neurona i svaki od njih ima ulogu da direktno promeni svoj ulazni signal pre nego što isti stigne u aktivacionu funkciju.

Mogućnosti primene neuronskih mreža u EES predstavljene su na slici 2. Kao što se može videti, postoji čitav niz veoma korisnih aplikacija, od kojih su najčešće prognoza opterećenja (25\%) i analiza kvarova (18\%).

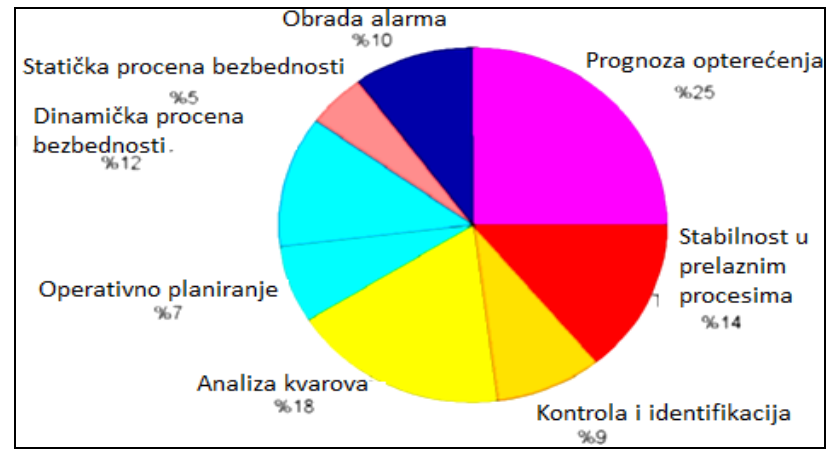

Slika 2. Primena neuronskih mreža u EES [3]

Veštačke neuronske mreže se u najopštijem smislu mogu podeliti na neuronske mreže sa prosleđivanjem unapred, rekurentne mreže i na njihove hibride.

\subsection{Neuronske mreže sa prosleđivanjem unapred}

Neuronske mreže sa prosleđivanjem unapred (eng. Feed Forward Neural Network - FFN) predstavljaju najjednostavniji tip neuronskih mreža. Kod njih je tok informacija jednosmeran i ide od ulaznih jedinica, prolazi kroz skrivene slojeve (ukoliko ih ima), do izlaznih jedinica, odnosno perceptrona (slika 3) [4]. Mogu biti jednoslojne i višeslojne.

Jednoslojna mreža perceptrona sastoji se od samo jednog izlaznog sloja, a ulazi se prosleđuju izlaznima preko niza težina. Suma proizvoda težina i stanja ulaza izračunava se u svakoj jedinici, pa ukoliko je vrednost iznad neke granične vrednosti (obično 0), neuron daje signal i preuzima aktiviranu vrednost (obično 1), dok u suprotnom, uzima deaktiviranu vrednost (obično -1) [5].

Višeslojni perceptroni sastoje se od više međusobno povezanih slojeva, tako da se informacije idu isključivo unapred. Svaki neuron u određenom sloju poseduje usmerene veze ka neuronima u narednom. Najčešće se u ovakvim mrežama primenjuje sigmoidna funkcija, kao funkcija aktivacije. Višeslojne mreže koriste veliki broj tehnika za obučavanje, od kojh najpoznatiju predstavlja metod propagacije unazad (eng. Back Propagation $B P)$. Izlazne vrednosti porede se sa tačnim vrednostima u cilju izračunavanja vrednosti neke predefinisane funkcije greške. S obzirom da se greška propagira unazad kroz mrežu, težinski faktori se ažuriraju, odnosno popravljaju kako bi se smanjila greška za neku malu vrednost. Slika 4 prikazuje model višeslojne FFN mreže.

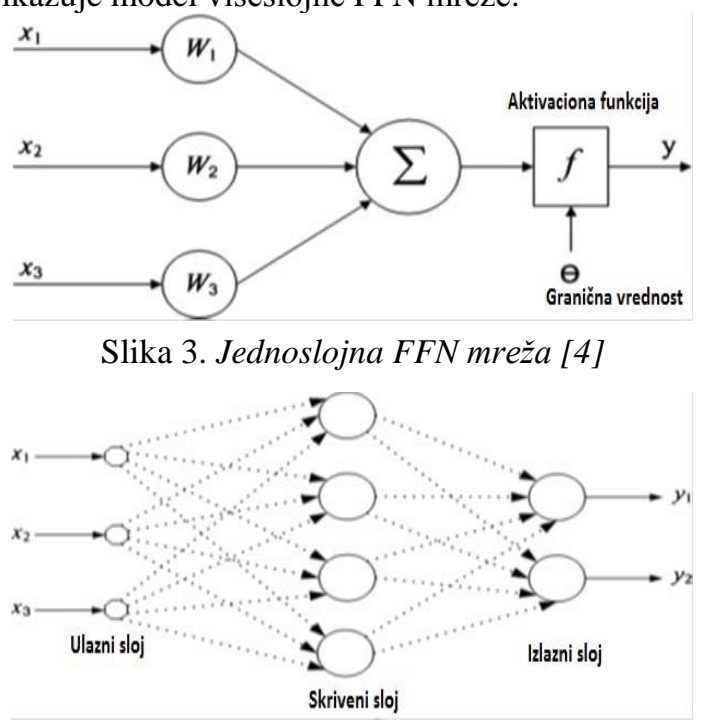

Slika 4. Višeslojna FFN mreža [4]

\subsection{Rekurentna neuronska mreža}

Nasuprot FFN mreži, rekurentne neuronske mreže (engl. Recurrent neural networks, RNN) predstavljaju modele sa dvosmernim protokom podataka, odnosno podaci se propagiraju od daljih stadijuma procesiranja ka ranijim. Slika 5 prikazuje izgled jedne RNN.

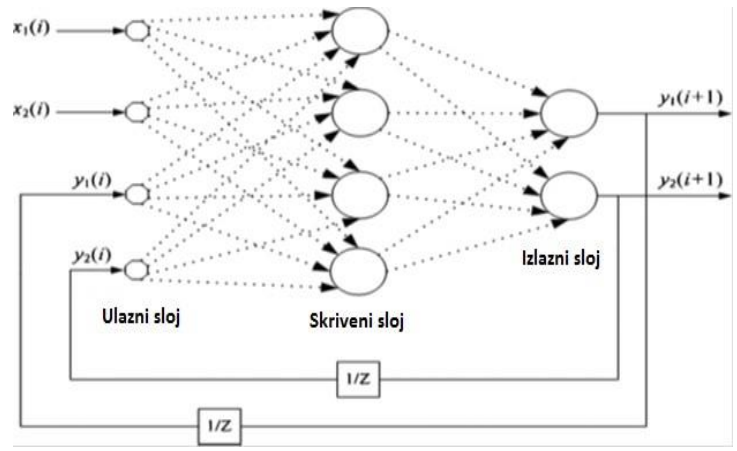

Slika 5. Rekurentna neuronska mreža [4] 


\subsection{Obučavanje neuronskih mreža}

Procedura koja služi za obučavanje neuronske mreže predstavlja algoritam obučavanja. Kroz ovu proceduru se na algoritamski (sistematski) način menjaju sinaptičke težine u cilju dostizanja željenih performansi. Ima više metoda učenja, od kojih je ovde primenjeno nadgledano učenje. Ono se karakteriše činjenicom da su uz ulazne vrednosti date i izlazne vrednosti koje im odgovaraju. Ulazne i izlazne vrednosti najčešće se predstavljaju $u$ vektorskom obliku i obično se označavaju sa $x$ i $y$, pri čemu se ulazne promenljive često nazivaju atributima, a izlazne ciljnim. U opštem slučaju, pretpostavka je da je odnos između ulaznih i izlaznih promenljivih dat zajedničkom raspodelom verovatnoće $(x, y)$. U najvećem broju slučajeva, pod ovom verovatnoćom podrazumeva se gustina raspodele. Obično ova raspodela nije dostupna, pa se iz tog razloga pristupa određivanju modela $f(x)$ koji ulaznim vrednostima pridružuje izlazne promenljive. Ovakvih modela može biti veliki broj, pa je od značaja najbolji takav model. Zbog ovoga, definiše se funkcija greške, koja se koristi za merenje odstupanja predviđenih i stvarnih vrednosti izlazne promenljive koja se označava sa $(y,(x))$. Greška koja se dešava na kombinacijama koje su verovatnije, ima veći značaj, pa se gustina raspodele kombinacija $(x, y)$ koristi za usrednjavanje grešaka, čime se definiše stvarni rizik [6].

$$
R(f)=E[L(y ; f(x))]=\int L(y, f(x)) p(x ; y) d x d y
$$

$\mathrm{S}$ obzirom da je pojmom rizika definisan kvalitet modela, neophodno je naći funkciju koja minimizuje rizik, odnosno rešava se problem:

$$
\min _{f}(f)
$$

\section{PRIMENA NEURONSKIH MREŽA ZA DETEKCIJU PROPADA U IEEE13 TEST MREŽI}

\subsection{Priprema podataka}

Nakon nekoliko pokretanja simulacija, sa ciljem da se prikupi dovoljna količina podataka, izvršeno je snimanje signala kvarova u korišćenom modelu (slika 1). Detekcija je izvršena analizom harmonijskog spektra naponskih signal (FFT). Blok je podešen tako da se traže niži harmonici, odnosno oni koji čine Harmonijski otisak i to u sve tri faze, na osnovu kojih se dalje vrši detekcija propada napona pomoću neuronske mreže. Taj signal je ubačen $\mathrm{u}$ bazu podataka $\mathrm{i}$ dalje se priprema, $\mathrm{u}$ vidu smeštanja podataka u matricu nad kojom je izvršeno transponovanje kako bi se prilagodila za ulaz u neuronsku mrežu. FFT blok prikazan je na slici 6 .

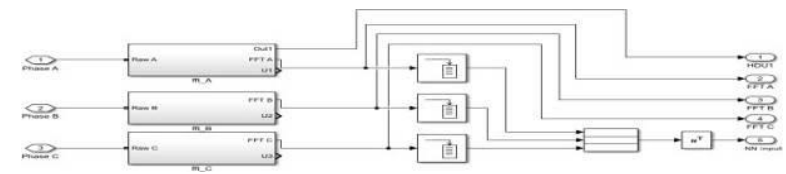

\section{S1. 6. FFT blok}

\subsection{Obučavanje}

Nakon što je obezbeđena baza podataka, u vidu signala napona za različite tipove propada, prelazi se na odabir tipa neuronske mreže i obučavanje iste. Za potrebe ovog rada, korišćena je jednostavna FFN neuronska mreža. Nalazi se u MATLAB-u pod nazivom Neural Net Pattern Recognition i koristi za kreiranje i obučavanje jednostavne dvoslojne FFN, sa ciljem da se izvrši detekcija propada napona u korišćenoj mreži. Baza podataka snimljenih propada unosi se u polje „Inputs“ u aplikaciji, kao na slici 7.

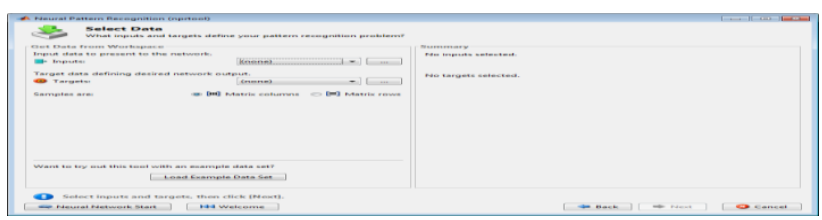

Slika 7. Unos podataka za neuronsku mrežu

Posle pripremljenih ulaznih podataka za neuronsku mrežu i podešavanja arhitekture, počinje njeno obučavanje. Obučavanje se vrši u 1000 epoha, što je podrazumevana vrednost ovog parametra. Početak obučavanja neuronske mreže prikazan je na slici 8 .

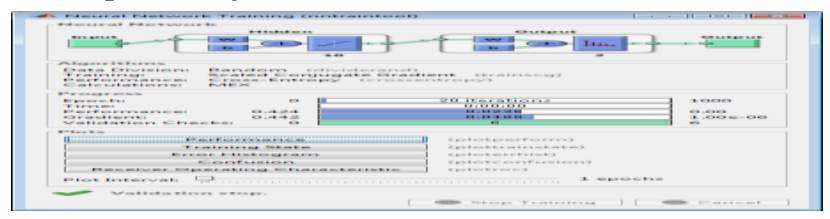

Slika 8. Obučavanje neuronske mreže

\subsection{Rezultati}

Izvršene su simulacije za dve vrste propada napona kao posledice jednopolnog kratkog spoja faze A sa zemljom (slučaj 1) i međufaznog kratkog spoja faze A i faze B (slučaj 2). Snimljeni su odzivi signala za detekciju primenom neuronskih mreža i pomoću standardne RMS metode. Celokupna simulacija traje $1 \mathrm{~s}$, pri čemu su kvarovi simulirani u periodu od $\mathrm{t}=0,08 \mathrm{~s}$ do $\mathrm{t}=0,24 \mathrm{~s}$.

\subsubsection{Jednopolni kratak spoj faze A sa zemljom}

Nakon što se dogodio kvar u $\mathrm{t}=0,08 \mathrm{~s}$, dolazi do izobličenja talasnog spektra napona sve tri faze, pri čemu se značajnija izobličenja javljaju upravo u fazama u kojima se dogodio kvar, što je u ovom slučaju faza A (slika 9).

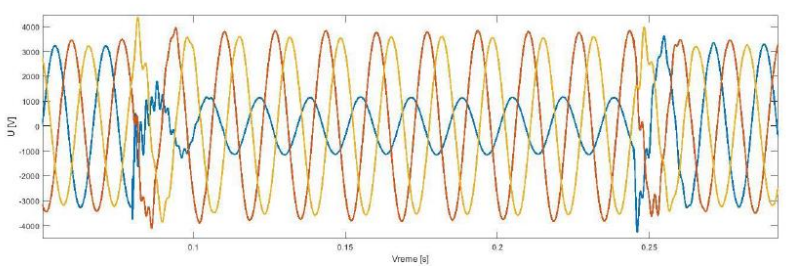

Slika 9. Talasni oblici napona za slučaj 1

Može se jasno uočiti da se u trenutku nastanka propada napona $(\mathrm{t}=0,08 \mathrm{~s})$, pojavljuje izobličenje (značajno učešće viših harmonika u talasnom obliku napona), koje se ponavlja u trenutku prestanka kvara, odnosno početka oporavljanja naponskih prilika $(\mathrm{t}=0,24 \mathrm{~s})$. Na slici 10 prikazani su ovi signali za svaku fazu, s tim da prvi impuls, odnosno izobličenje za $\mathrm{t}=0 \mathrm{~s}$ treba zanemariti, jer je posledica početnog oscilovanja modela, a ne kvara u mreži.

Ova izobličenja (po fazama) predstaljvaju signal neuronskoj mreži da se dogodio propad napona i ona generiše signal 1 . Na slici 11 vidi se da neuronska mreža (FNN) generiše signal 1 kada je detektovala propad $(t=0,08067 \mathrm{~s})$ i kada je prestao (impuls $\mathrm{u} t=0 \mathrm{~s}$ je vezan za početne oscilacije modela i zanemaruje se). Može se zaključiti da je neuronska mreža uspešno detektovala pojavu propada $i$ to za svega $\Delta \mathrm{t}=0,67 \mathrm{~ms}$. 


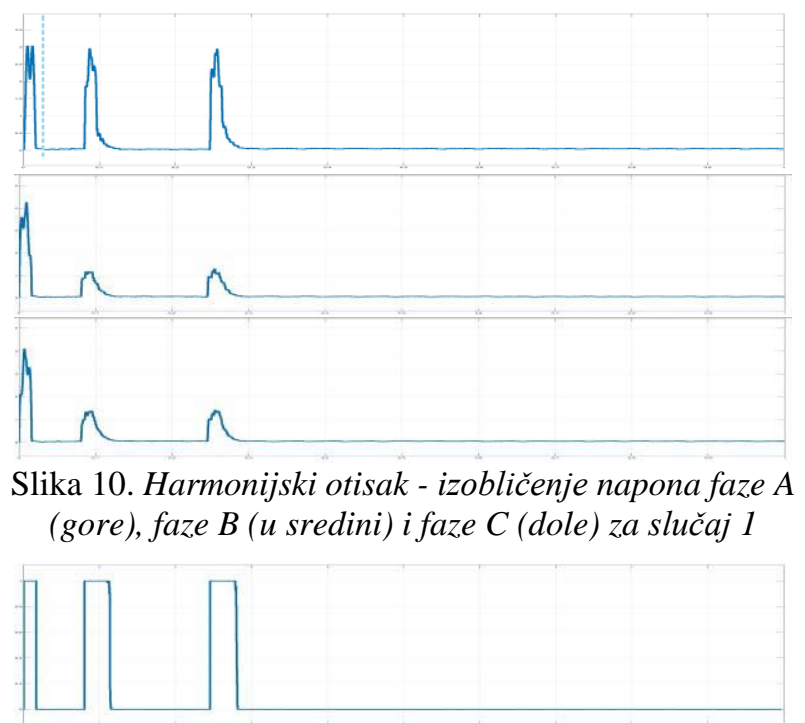

Slika 11. Izlazni signal bloka neuronske mreže (slučaj 1)

Radi poređenja, urađena je simulacija detekcije istog propada napona pomoću standardne RMS metode. Rezultat je prikazan na slici 12 . Vidi se RMS napona faze A opada na vrednost manju od $90 \%$ nominalne $\mathrm{u} t=0,1 \mathrm{~s}$, što kada se uzme $\mathrm{u}$ obzir da je trenutak nastanka propada definisan $\mathrm{u}$ $\mathrm{t}=0,08 \mathrm{~s}$, pokazuje da je vreme detekcije $\Delta \mathrm{t}=20 \mathrm{~ms}$.

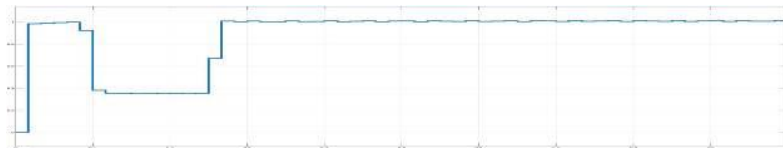

Slika 12. RMS metoda detekcije propada-slučaj 1

\subsubsection{Međufazni kratak spoj faze A i faze B}

U slučaju 2, nakon što se dogodio kvar u fazama A i B u trenutku $\mathrm{t}=0,08 \mathrm{~s}$, dolazi do izobličenja talasnih oblika napona (slika 13). Odgovarajući Harmonijski otisak prikazan je na slici 14 , za sve tri faze. Izlazni signal neuronske mreže, kao i odziv dobijen RMS metodom prikazani su na slikama 15 i 16 . Vidi da je FNN detektovala propad za svega $\Delta \mathrm{t}=0,65 \mathrm{~ms}$, dok je primenom RMS metode bilo potrebno opet $\Delta \mathrm{t}=20 \mathrm{~ms}$.

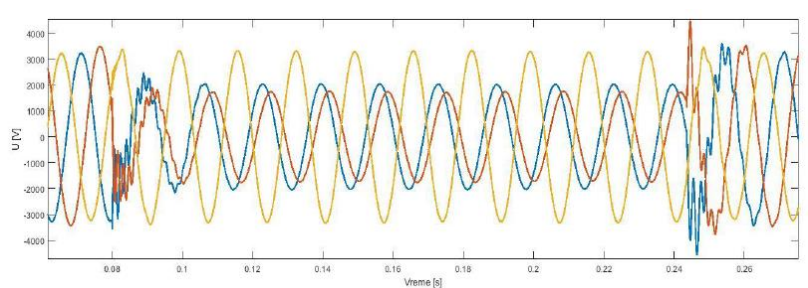

Slika 13. Talasni oblici napona za slučaj 2

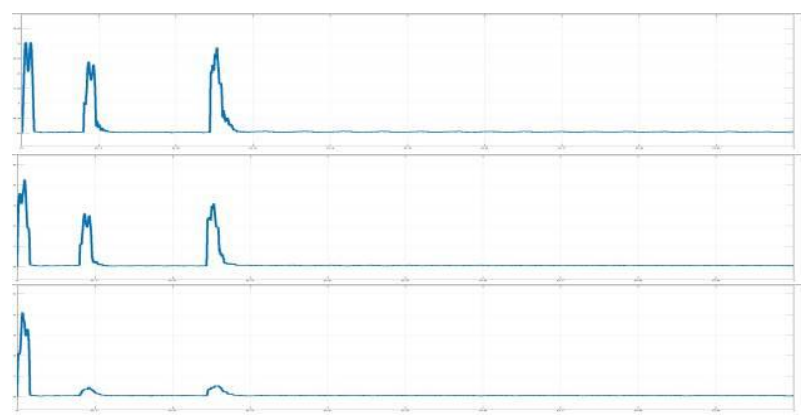

Slika 14. Harmonijski otisak - izobličenje napona faze A (gore), faze B (u sredini) i faze C (dole) - slučaj 2

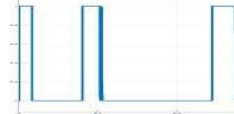

Slika 15. Izlazni signal bloka neuronske mreže - slučaj 2

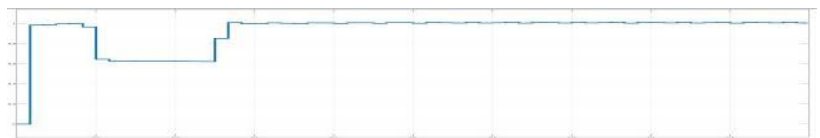

Slika 16. RMS metoda detekcije propada - slučaj 2

\section{ZAKLJUČAK}

Pametne tehnologije imaju sve veću primenu u svim sferama života, pa tako i u elektroenergetici. U budućnosti, može se očekivati dodatna ekspanzija primene pametnih tehnologija, primena neuronskih mreža.

Rezultat rada pokazao je da neuronske mreže mogu uspešno detektovati svaku vrstu propada napona značajno brže od standardne RMS metode.

\section{LITERATURA}

[1] D. J. Đozić: „Upotreba veštačkih neuronskih mreža za predviđanje ponašanja i upravljanje složenim elektroenergetskim sistemima“, Fakultet tehničkih nauka, Doktorska disertacija, Novi Sad, 2020.

[2] V. A. Katić, A.M. Stanisavljević, "Smart Detection of Voltage Dips Using Voltage Harmonics Footprint", IEEE Transaction on Industry Application, Vol.54, No.5, Sep./Oct. 2018, pp.5331-5342,

[3] M. T. Hagh: "Application of Neural Networks in Power Systems", WAS, Engineering and Technology, No.6 2005, pp.53-57.

[4] L. H. Hassan, M. Moghavvemi, Haider A.F. Almurib, Otto Steinmayer: "Current state of neural networks applications in power system monitoring and control"

[5] K.-L. Du, M.N.S. Swamy: "Neural Networks and Statistical Learning”, Springer-Verlag London, 2014.

[6] M. M. Milosavljević: „Veštačka inteligencija“, Univerzitet Singidunum, Beograd, 2015.

\section{Kratka biografija:}

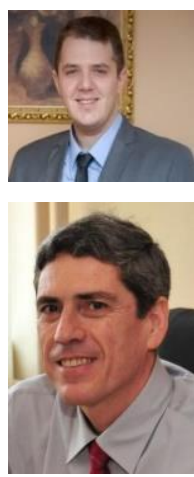

Ivan Vasić rođen je 1996. god. u Smederevu. Osnovne studije završio je na Fakultetu tehničkih nauka 2019. god., a master 2020. god. iz oblasti Elektrotehnike i računarstva.

Vladimir A. Katić rođen je 1954. god. u Novom Sadu. Doktorirao je na Univerzitetu u Beogradu 1991. god. Od 2002. god. je redovni profesor Univerziteta u Novom Sadu. Oblasti interesovanja su mu energetska elektronika, kvalitet električne energije, obnovljivi izvori električne energije i električna vozila.

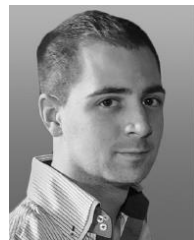

Aleksandar M. Stanisavljević, rođen je u Beogradu 1988. god. Doktorirao ne na Univerzitetu u Novom Sadu 2019. god. gde je trenutno u zvanju docenta. Oblast interesovanja su mu integracija obnovljivih izvora energije na mrežu i kvalitet električne energije. 